\title{
Age-differences in odor preference following an odor-illness pairing
}

\author{
WILLIAM A. VALLIERE, CINDY S. PETERSON, and JAMES R. MISANIN \\ Susquehanna University, Selinsgrove, PA
}

and

\author{
CHARLES F. HINDERLITER \\ The University of Pittsburgh, Johnstown, PA
}

\begin{abstract}
An ambient maple odor was paired with illness in rats ranging in age from weaning to old age. The animals then were tested for an aversion to a maple-odored solution. The results indicated no aversion to the odored solution at any age level and, hence, support previous research indicating that odor is a weak cue for illness. However, both young-adult and old-age rats made ill after drinking water in the absence of odor preferred the maple-odored solution to plain water. This finding suggests that, whereas odor may be a weak cue for illness in adult rats, it may be an effective safety signal. In contrast, weanling rats made ill in the presence of the odor preferred the odored solution. This paradoxical preference was explained in terms of olfactory imprinting and the effect punishment has on imprinted responses.
\end{abstract}

When rats are exposed to a novel odor, even for a brief period of time, their subsequent preference for that odor increases. There appears to be little variation in this effect in rats ranging from infancy to adulthood (Caza \& Spear, 1984). However, if the novel odor is paired with an illness-inducing agent, then there are striking differences in odor preferences for rats of different age groups. When illness follows odor in adult rats, there is very little change in preference for the odor. Odor appears to be a weak signal for illness for these animals (Garcia \& Koelling, 1967; Hankins, Garcia, \& Rusiniak, 1973). In infant rats, on the other hand, odor is such an effective cue for illness that even second-order odor aversions are easily established (Cheatle \& Rudy, 1978, 1979). Unlike adults, infant rats are highly dependent upon olfaction for a variety of behaviors (e.g., sucking, homing, etc.), and, hence, differences in the effectiveness of odor as a signal for illness may reflect the fact that olfactory cues are more salient for infant rats than for adults. The salience of olfactory cues should decrease for the rat as its reliance on olfactory input diminishes with the development of other sensory systems. Because a variety of the rat's sensory systems (e.g., visual, auditory, etc.) become functional well before the postweaning period (Alberts, 1984), it would seem that there should be little or no difference in the effectiveness of odor as a cue for illness in rats from weaning to old age, assuming of course that the olfactory system remains functional. Recently, however, Misanin, Peterson, Valliere, Blatt, and Hinderliter (1985) reported differences in the effect odor has on conditioned taste aver-

Please address correspondence to: J. R. Misanin, Psychology Department, Susquehanna University, Selinsgrove, PA 17870. sion in weanling, young-adult, and old-age rats. Odor had a strong potentiating effect on the aversion to taste in young adults, had a weaker potentiating effect in weanlings, and had no effect in old-age rats. It is possible, then, that the effects of age in processing odor cues persist well into the postweanling period. Thus, the purpose of the present experiment was to determine whether there are differences due to age in responsiveness to odor paired with illness in rats ranging from weaning to old age.

We planned to use an ambient odor during conditioning instead of an olfactory solution (e.g., Durlach \& Rescorla, 1980) to avoid the possibility that rats would respond to taste rather than odor. Research demonstrating that rats responded to an olfactory solution primarily on the basis of odor used rats only within the young-adult age range (Rusiniak, Hankins, Garcia, \& Brett, 1979).

\section{METHOD}

\section{Subjects}

Forty female Wistar-derived albino rats at each of three age levels (21-25 days, weanling; 93-121 days, young-adult; 847-989 days, oldage) served as subjects. Throughout the experiment, the animals had free access to food except during drinking sessions that were $1 \mathrm{hr}$ or less. The animals were maintained on a 23- to 24-h water deprivation schedule. Three to four animals were housed in like-age groups in standard galvanized suspended rodent cages. The animals were housed in the room in which the drinking sessions took place. On the days on which odor was to be presented, the animals' home rack was moved to another room and remained there until $1 / 2 \mathrm{~h}$ after the drinking session. In the room in which the drinking sessions took place, there was a complete exchange of air every $20 \mathrm{~min}$.

\footnotetext{
Apparatus

All drinking sessions took place in galvanized suspended rodent cages that were similar to home cages except that the drinking cages were equipped with four spring-grip clamps to hold water cylinders and a 25-mm-diam metal cap that housed a cotton ball on which the maple
} 
odor (.1 ml Wagner's Artificial Maple Flavor) was placed. The cap was situated $3 \mathrm{~cm}$ below the drinking spout of a 100 -ml cylinder that was located at the center of the front of the cage. The other two clamps on the front of the cage were $35 \mathrm{~mm}$ from each side. These were used to hold two 100-ml cylinders on the test day. The cylinders were equipped with rubber stoppers and stainless steel sipper tubes.

\section{Procedure}

Initially the rats were weighed, ear-notched for identification, and placed on a 23-h water deprivation schedule. They were then given three daily 1-h adaptation sessions during which they had access to room temperature tap water in the drinking cages. Before all drinking sessions, the animals were weighed; during all drinking sessions, the animals were individually housed. The day following the last adaptation session, they were given experimental or control treatments. Both types of treatment involved placing the animal in the drinking cage for $10 \mathrm{~min}$ with access to room-temperature tap water. The experimental group $(\mathrm{N}=10)$ at each age level had the maple odor (.1 ml of Wagner's Artificial Maple flavor on the cotton ball) present during their 10-min access to water. Immediately after the 10-min access to odor and water, the experimental animals were given a $1 \%$ body weight intraperitoneal injection of $.15 \mathrm{M} \mathrm{LiCl}$. One control group $(\mathrm{N}=10)$ at each age level was treated identically, except that these control animals were injected with physiological saline instead of $\mathrm{LiCl}$. Two other control groups ( $\mathrm{N}=10$ /group) at each age level did not experience the odor; one of these was injected with $\mathrm{LiCl}$ and the other with saline immediately following 10 -min access to tap water. Approximately $24 \mathrm{~h}$ after these experimental and control treatments, all animals were given a 24-h two-bottle test. One cylinder contained plain tap water; the other contained a $1 \%$ maple $(v / v$ in tap water) solution. The amount of each solution drunk by each animal was recorded at 1, 6, 18, and $24 \mathrm{hr}$. After the first hour, the animals had free access to food.

\section{RESULTS}

The amount of plain and maple tap water drunk by each rat was converted to a preference score [Ma$\mathrm{ple} /($ maple+ plain) $\times 100]$ and averaged for groups. Results are depicted in Figure 1. A split-plot factorial ANOVA was performed on these preference data with age (weanling vs. young adult vs. old age), odor condition (odor vs. no odor), and type of injection ( $\mathrm{LiCl}$ vs. saline) as the between-subjects variables, and access time
$(1,6,18$, and $24 \mathrm{~h})$ as the within-subjects variable. With the significance level set at .05 , this analysis yielded significant main effects of odor condition and type of injection $[\mathrm{Fs}(1,108)>4.06]$, indicating that animals of all ages were sensitive to the odor and differentially responsive to saline and $\mathrm{LiCl}$. In general, however, animals drank less of the maple if they had previous experience with it and more of it if they had been injected with $\mathrm{LiCl}$. Comparison of $\mathrm{LiCl}$ and saline treatments within like-odor conditions indicated that there was no conditioned odor aversion in the odor- $\mathrm{LiCl}$ groups at any age level. In fact, the weanlings that were injected with $\mathrm{LiCl}$ in the presence of maple odor drank more of the maple solution than did the saline controls $[\mathrm{F}(1,108)=5.89]$ and, in contrast to adults, their preference for the olfactory solution increased over time $[\mathrm{F}(3,324)=5.14]$. However, comparisons of the two LiCl-treated groups at each age level showed that, in both young-adult and oldage rats, those that were injected with $\mathrm{LiCl}$ in the absence of odor showed a significantly greater preference for the maple solution than did those that were injected with $\mathrm{LiCl}$ in the presence of odor $[\mathrm{Fs}(1,108)>3.82]$.

\section{DISCUSSION}

The results of the present experiment indicate that age-related differences in the rats' responsiveness to odor persist into the postweaning period. The present findings support previous research showing that odor is a weak cue for illness in adult rats (Garcia \& Koelling, 1967; Hankins et al, 1973). Adults poisoned in the presence of the ambient maple odor showed little or no aversion for the maple-odored solution. In contrast, both young-adult and old-age poisoned in the absence of the ambient odor preferred the odored solution during the 24-h test. This significant difference between the two $\mathrm{LiCl}$-treated groups at the young-adult and old-age levels suggests that, whereas odor may be an ineffective cue for illness in adult rats, it may be an effective safety signal. Weanling rats that were injected with $\mathrm{LiCl}$ in the presence of odor, on the other hand, drank as much of the odored solution as did those poisoned in the absence of odor, and both LiCl-treated groups showed a preference for the odored solution. A similar illness-induced preference was observed by Martin and Alberts (1979) when $\mathrm{LiCl}$ followed dis-

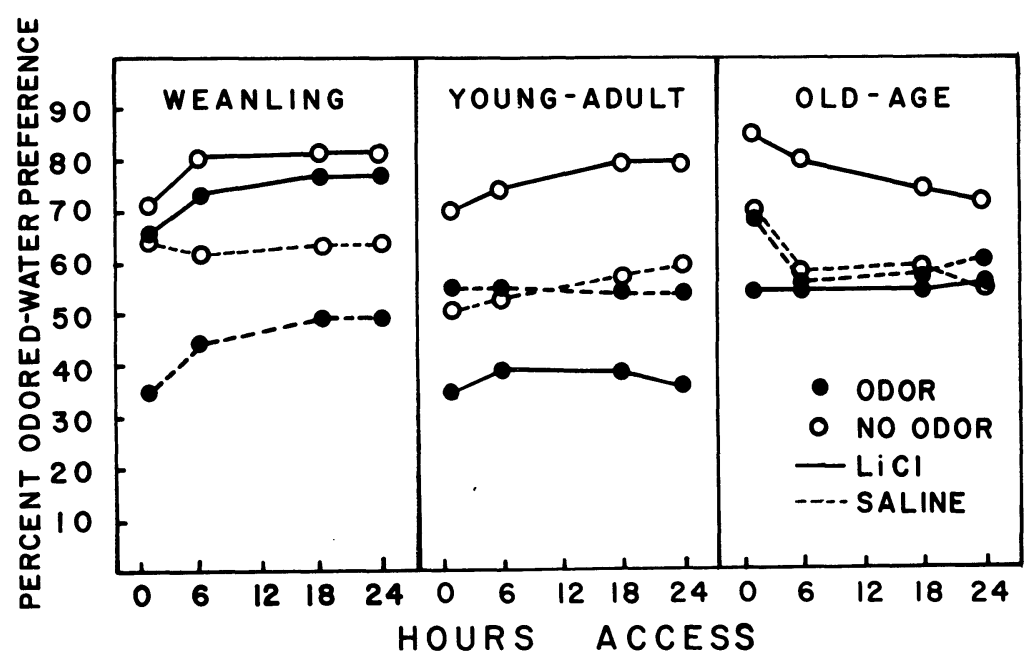

Figure 1. Percent preference for the olfactory (maple) solution as a function of age, conditioned stimulus (ambient maple odor vs. no odor), unconditioned stimulus (LiCl vs. saline), and hours access. 
tinctive cues in mother's milk during nursing. These investigators suggested that the paradoxical preference may have been due to an illnessinduced increase in arousal or "learned familiarity" effect (Best \& Barker, 1977) resulting from illness-induced priming of the taste representation in short term memory. Alternatively, because infant rats are dependent on olfactory cues for sucking, it is possible that the paradoxical taste preference observed by Martin and Alberts was the result of a $\mathrm{LiCl}-$ induced odor preference. A LiCl-induced preference for an odor can possibly be explained by the effect that punishment has on imprinting. Punishment tends to fixate rather than interfere with an imprinted response (Kovach \& Hess, 1963), and there is some evidence that infant rats not only undergo olfactory imprinting to the maternal surround shortly after birth (Schapiro \& Salas, 1970), but that they respond to familiar non-nest odors much as they respond to nest odors (Wigal, Kucharski, \& Spear, 1984). Thus, when paired with odor, LiCl may serve as a punisher and fixate the approach response to odor. There is, in fact, evidence that punishment does tend to fixate the approach response to familiar nest odors and other home environmental stimuli (Collier, Mast, Meyer, \& Jacobs, 1979; Peterson, Benton, Gordon, Misanin, \& Hinderliter, 1985). Collier et al. (1979) found rat pups to continue to approach a dam even though they were punished for doing so, and Peterson et al. (1985) reported that preweanlings persisted in running to homecage shavings located in the nonreinforced endbox in an aversively motivated spatial discrimination task. Thus, in the present study, it is possible that the punishing effect of $\mathrm{LiCl}$ or an illness-induced increase in arousal caused the weanling rat to regress to an earlier pattern of behavior. Regardless of the mechanism, however, the present results clearly indicate that weanling rats differ from adults in their responses to an odor previously paired with illness.

\section{REFERENCES}

AlberTs, J. R. (1984). Sensory-perceptual development in the Norway rat: A view toward comparative studies. In R. Kail and N. E. Spear (Eds.), Comparative perspectives on the development of memory. Hillsdale, NJ: Erlbaum.

BeST, M. R., \& BARKER, L. M. (1977). The nature of "learned safety" and its role in the delay of reinforcement gradient. In L. M. Barker, M. R. Best, \& M. Domjan (Eds.), Learning mechanisms in food selection. Waco, TX: Baylor University Press.

CAZA, P., \& SPEAR, N. (1984). Short-term exposure to an odor increases its subsequent preference in preweanling rats: A descriptive profile of the phenomenon. Developmental Psychobiology, 17, 407-422.

Cheatle, M. D., \& Rudy, J. W. (1978). Analysis of second-order con- ditioning in neonatal rats: Implications for Kamin's blocking effect. Journal of Experimental Psychology: Animal Behavior Processes, 4, 237-249.

Cheatle, M. D., \& Rudy, J. W. (1979). Ontogeny of second-order odor-aversion conditioning in neonatal rats. Journal of Experimental Psychology: Animal Behavior Processes, 5, 142-151.

Collier, A. C., Mast, J., Meyer, D. R., \& JaCobs, C. E. (1979). Approach-avoidance conflict in preweanling rats: A developmental study. Animal Learning \& Behavior, 7, 514-520.

Durlach, P. J., \& Rescorla, R. A. (1980). Potentiation rather than overshadowing in flavor-aversion learning: An analysis in terms of within-compound associations. Journal of Experimental Psychology: Animal Behavior Processes, 6(2), 175-187.

GaRCIA, J., \& KoElling, R. (1967). A comparison of aversions induced by $\mathrm{X}$ rays, toxins, and drugs in the rat. Radiation Research Supplement, 7, 439-450.

Hankins, W. G., Garcia, J., \& Rusiniak, K. W. (1973). Dissociation of odor and taste in baitshyness. Behavioral Biology, 8, 407-419.

KovACH, J. K., \& Hess, E. H. (1963). Imprinting: Effects of painful stimulation upon the following response. Journal of Comparative \& Physiological Psychology, 56, 461-464.

MarTin, L. T., \& AlberTs, J. R. (1979). Taste aversions to mother's milk: The age-related role of nursing in acquisition and expression of a learned association. Journal of Comparative \& Physiological Psychology, 93, 430-445.

Misanin, J. R., Peterson, C. S., Valliere, W., Blatt, L. A., \& Hinderliter, C. F. (1985, March). Potentiation of taste aversion by odor cues. Paper presented at the meeting of the Eastern Psychological Association, Boston.

Peterson, C. S., Benton, N., Gordon, I., Misanin, J. R., \& HinDERLITER, C. (1985, March). The role of homecage environmental stimuli in the facilitation of shock-motivated spatial discrimination in rat pups. Paper presented at the meeting of the Eastern Psychological Association, Boston.

Rusiniak, K. W., Hankins, W. G., Garcia, J., \& Brett, L. P. (1979). Flavor-illness aversions: Potentiation of odor by taste in rats. Behavioral \& Neural Biology, 25, 1-17.

Schapiro, S., \& Salas, M. (1970). Behavioral response of infant rats to maternal odors. Physiology and Behavior, 5, 815-817.

Wigal, T., KuCharski, D., \& SPEAR, N. E. (1984). Familiar contextual odors promote discrimination learning in preweanling but not in older rats. Developmental Psychobiology, 17, 555-570.

(Manuscript received for publication April 15, 1985.) 